\title{
A PESQUiSA EM ESTRATÉgIA E SUSTENTABILIDADE: PROPOSTA DE AGENDA DE PESQUISA A PARTIR DE UM ESTUDO BIBLIOMÉTRICO
}

\section{RESUMO}

Este trabalho teve como objetivo compreender a estrutura intelectual que conecta os temas Estratégia e Sustentabilidade, a partir da análise da produção acadêmica em periódicos de alto fator de impacto, por intermédio de uma pesquisa bibliométrica. A justificativa deste estudo se deve ao fato da aparente inexistência de uma revisão que conecte a relação de estratégia e sustentabilidade, apesar de muitos pesquisadores reconheçam o tema como um desafio estratégico para as empresas. O método de pesquisa foi o bibliométrico e a coleta de dados ocorreu na plataforma ISI Web of Science. De acordo com os resultados, a publicação de artigos sobre estratégia e sustentabilidade tem aumentado consideravelmente nos últimos anos. Os resultados indicam que três bases intelectuais têm influenciado o estudo de estratégia e sustentabilidade: a primeira trata da relação da sustentabilidade e competitividade; a segunda está relacionada aos recursos/capabilities para a vantagem competitiva com sustentabilidade; a terceira, a influência do ambiente na vantagem competitiva considerando a sustentabilidade. Ao final se sugere um conjunto de estudos futuros com base nos resultados.

Palavras-chave: Sustentabilidade; Estratégia; Vantagem Competitiva; Gestão Sustentável; Bibliometria.

\section{RESEARCH IN STRATEGY AND SUSTAINABILITY: PROPOSAL OF A RESEARCH AGENDA FROM A BIBLIOMETRIC STUDY}

\begin{abstract}
This work aimed to understand the intellectual structure that connects the themes of Strategy and Sustainability, from the analysis of academic production in high impact factor journals, through a bibliometric research. The justification for this study is due to the fact that there is no review that connects the strategy and sustainability relationship, although many researchers recognize the theme as a strategic challenge for companies. The research method was bibliometric and data collection took place on the ISI Web of Science platform. According to the results, the publication of articles on strategy and sustainability has increased considerably in recent years. The results indicate that three intellectual bases have influenced the study of strategy and sustainability: the first deals with the relation of sustainability and competitiveness; The second is related to the resources / capabilities for the competitive advantage with sustainability; The third, the influence of the environment on the competitive advantage considering sustainability. A set of future studies based on the results is suggested.
\end{abstract}

Keywords: Sustainability; Strategy; Competitive Advantage; Sustainable Management; Bibliometrics. 


\section{LA INVESTIGACIÓN EN ESTRATEGIA Y SOSTENIBILIDAD: PROPUESTA DE AGENDA DE INVESTIGACIÓN A PARTIR DE UN ESTUDIO BIBLIOMÉTRICO}

\section{RESUMEN}

Este trabajo tuvo como objetivo comprender la estructura intelectual que conecta los temas Estrategia y Sostenibilidad, a partir del análisis de la producción académica en periódicos de alto factor de impacto, por intermedio de una investigación bibliométrica. La justificación de este estudio se debe al hecho de la aparente inexistencia de una revisión que conecte la relación de estrategia y sostenibilidad, a pesar de que muchos investigadores reconocen el tema como un desafío estratégico para las empresas. El método de investigación fue el bibliométrico y la recolección de datos se produjo en la plataforma ISI Web of Science. De acuerdo con los resultados, la publicación de artículos sobre estrategia y sostenibilidad ha aumentado considerablemente en los últimos años. Los resultados indican que tres bases intelectuales han influenciado el estudio de estrategia y sostenibilidad: la primera trata de la relación de la sostenibilidad y competitividad; la segunda está relacionada con los recursos / capacidades para la ventaja competitiva con sostenibilidad; la tercera, la influencia del ambiente en la ventaja competitiva considerando la sostenibilidad. Al final se sugiere un conjunto de estudios futuros basados en los resultados.

Palabras clave: Sostenibilidad; Estrategia; Ventaja competitiva; Gestión sostenible; Bibliometría.

Luana da Silva Marques ${ }^{1}$ Claudia Terezinha Kniess ${ }^{2}$ Silvia Regina Meira ${ }^{3}$ Mauro Silva Ruiz ${ }^{4}$

\footnotetext{
${ }^{1}$ Mestranda do Programa de Mestrado Profissional em Gestão Ambiental e Sustentabilidade da Universidade Nove de Julho - PMPA-GeAS/UNINOVE. Brasil. E-mail: luamarq@yahoo.com.br

${ }^{2}$ Doutora em Ciência e Engenharia de Materiais pela Universidade Federal de Santa Catarina - UFSC. Diretora do Programa de Pós-graduação em Cidades Inteligentes Sustentáveis da Universidade Nove de Julho - PPGCIS/UNINOVE. Brasil. E-mail: ctkniess@uni9.pro.br

${ }^{3}$ Mestranda do Programa de Mestrado Profissional em Gestão Ambiental e Sustentabilidade da Universidade Nove de Julho - PMPA-GeAS/UNINOVE. Brasil. E-mail: silvia@biotechambiental.com.br

${ }^{4}$ Doutor em Geografia pela Southern Illinois University at Carbondale, Estados Unidos. Diretor do Programa de Mestrado Profissional em Gestão Ambiental e Sustentabilidade da Universidade Nove de Julho - PMPAGeAS/UNINOVE. Brasil. E-mail: maurosilvaruiz@uni9.pro.br
} 


\section{INTRODUÇÃO}

A preocupação com a conservação do meio ambiente é antiga, mas passou a ganhar força a partir da segunda metade do século passado (Hart, 1980). Somente a partir da década de 1990 a discussão da sustentabilidade passou a ser considerada em relação à estratégia das empresas (Bansal, 2002; Dyllick \& Hockerts, 2002), pela maior conscientização ecológica por parte da sociedade (Dunlap \& Mertig, 1992; Hart, 2005; Shrivastava \& Hart, 1994). Houve intensificação de estudos que tratavam da importância das empresas para o desenvolvimento sustentável (Hahn, Figge, Liesen, \& Barkemeyer, 2010) e dos benefícios que as práticas sustentáveis trariam para as empresas (Wagner, 2010).

Autores argumentaram ainda da importância das empresas para resolver o desafio da sustentabilidade (Hart \& Shrivastava, 1995; Hart \& Milstein, 1999; Hahn, Figge, Pinkse, \& Preuss, 2010), mas apesar desta importância, as abordagens teóricas de estratégia têm sido criticadas por não considerarem as restrições impostas pelo meio ambiente natural e pelo subdesenvolvimento social (Hart \& Shrivastava, 1995). Os trabalhos acadêmicos sobre o tema também cresceram neste período, assim como novos periódicos dedicados á temática foram criados. Esta temática também tem sido considerada no Brasil e nas divisões da Associação Nacional de Pós-graduação e Pesquisa (Anpad), onde a Sustentabilidade foi tema explícito na área de Estratégia e Organizações (ESO), Gestão de Operações e Logística (GOL) e Gestão de Ciência, Tecnologia e Inovação (GCT) a partir de então.

Pelo exposto, e na crença de que a competitividade das empresas passa a ter que incorporar a sustentabilidade e a relação com a sua estratégia (Christmann, 2000; McGee, 1998), até para avaliar novas formas de vantagem competitiva pelo desenvolvimento de capabilities (Aragón-Correa \& Sharma, 2003; Berry \& Rondinelli, 1998; Sharma, Moody, \& Rosa, 2003; Sharma \& Vredenburg, 1998), este estudo buscou responder á questão de pesquisa: Quais são os principais temas nas pesquisas sobre Sustentabilidade e Estratégia analisando-se a produção acadêmica cientifica á partir de periódicos de alto fator de impacto? O objetivo principal foi $\mathrm{o}$ de compreender a estrutura intelectual que conecta os temas Estratégia e Sustentabilidade, pela análise da produção acadêmica em periódicos de alto fator de impacto, nas áreas de Administração e Sustentabilidade. Os objetivos específicos foram avaliar a contribuição da pesquisa sobre Sustentabilidade e Estratégia a partir de estudo bibliométrico de citação e cocitação; analisar os principais temas nos estudos de Sustentabilidade e Estratégia, verificando as tendências encontradas a partir das abordagens teóricas utilizadas e emergentes no tema por meio da análise fatorial exploratória; e apresentar uma agenda de pesquisas futuras sobre o tema. Para tanto, utilizado um estudo bibliométrico, com análise de citação, cocitação e análise fatorial, na base ISI Web of Science (ISI) até 2014.

Os resultados da pesquisa mostraram que houve um incremento de artigos publicados na temática á partir de 2010, sendo este um período importante a se analisar. A análise fatorial para o período amostral total (de 1971 a 2014) apresentou 3 fatores ou subtemas, a saber: Fator 1: Sustentabilidade e Competitividade; Fator 2: Recursos, Capabilities e Vantagem Competitiva; Fator 3: Influência do Ambiente na Vantagem Competitiva considerando a Sustentabilidade. As análises fatoriais por períodos confirmaram os temas elencados na análise fatorial do período total, sendo que no período mais recente, de 2010-2014, apareceram temas novos como capacidades dinâmicas , rotinas organizacionais e estratégicas.

O trabalho foi organizado de maneira a apresentar sequência considerando sua especificidade como artigo de revisão, mas mesmo em se tratando disto, optou-se por apresentar um referencial teórico orientativo sobre o tema. Na sequencia, apresentou-se a seção de dados e métodos, seguindo para apresentação dos resultados considerando a base intelectual de Estratégia e Sustentabilidade, refletindo o mainstream do tema. Finalizou-se com uma discussão conclusiva, apresentando possíveis pesquisas futuras sobre a área estudada.

\section{REFERENCIAL TEÓRICO}

$\mathrm{O}$ argumento fundamental para a ligação entre estratégia e sustentabilidade é o de que somente por intermédio do suporte das corporações a sociedade poderá experimentar o desenvolvimento sustentável (Bansal, 2002). Os estudos de sustentabilidade com apelo para as organizações despontaram a partir da década de 1990 (Carrol, 1999), principalmente com a emergência e dominância da RBV, sobretudo a partir desta década (Hoskinson et al., 1999).

Vários autores defendem a sustentabilidade como aspecto a ser incorporado na estratégia das empresas e consideraram que estas estratégias deveriam incluir a criação de valor a partir de perspectivas econômicas, sociais e ecológicas (Dyllick \& Hockerts, 2002), requerendo uma nova forma de pensar as oportunidades com uma nova perspectiva sobre estratégia, tecnologia e mercados (Hart, \& Milstein, 1999). Diversos trabalhos também procuram relacionar o desempenho ambiental ao desempenho da empresa (Porter, \& Van der Linde, 1995, 1995a; Hart, 1995). Russo, \& Fouts (1997) argumentaram que o desempenho ambiental e econômico estão 
positivamente relacionados, e que o crescimento do setor modera esta a relação.

Porém, apesar deste efeito positivo, Hart (1995) alertou da necessidade de resolver lacunas do desenvolvimento teórico em estratégia que ignoravam as restrições ambientais, e propôs a Visão Baseada em Recursos Naturais (Natural-Resource-Based View $N R B V$ ). Ketchen e Wright (2011) acrescentaram que os negócios no futuro estarão restritos e pressionados pelos desafios ambientais, fundamentalmente pelas limitações e degradações dos ecossistemas da natureza e que, por isso, a vantagem competitiva no futuro terá que ser suportada por capabilities que possibilitem a atividade econômica ambientalmente sustentável.

A sustentabilidade não pode ficar à margem das políticas públicas e Porter e Van Der Linde (1995) argumentam sobre a necessidade de um passo adiante em relação ao trade-off da regulação e da competitividade voltada para a produtividade de recursos, mudando o foco de custos para a avaliação dos benefícios das inovações. Palmer, Oates e Portney (1995) defenderam a regulamentação do meio ambiente, não fazendo referência aos benefícios sociais e contrapondo que os programas ambientais precisam justificar seus custos pelos benefícios de melhoria na qualidade ambiental para a sociedade.

Apesar da existência de diversas revisões anteriores e mesmo com a reconhecida importância da relação entre sustentabilidade e estratégia, não existe menção explícita sobre a temática em conjunto (Assan et al., 2015).

\section{MÉTODO}

\section{Procedimentos de coleta de dados}

Para a seleção dos artigos relevantes na temática, foi feita a seleção intencional de periódicos internacionais que fossem os mais expressivos na área de Administração e que tivessem altos Fatores de Impacto $(\mathrm{FI} \geq 1,4)$. A ISI Web of Science foi à base considerada para a seleção, pois além da abrangência de conteúdos, disponibiliza metadados facilitando o esforço amostral e a operacionalização.

Foram selecionados inicialmente os 25 periódicos em Administração que, após filtragem, totalizaram 13 para a amostragem. Vale ressaltar que alguns autores de trabalhos anteriores usaram somente um periódico relevante para a busca (ver Nerur; Rasheed; Natarajan, 2008; Ramos-Rodríguez; RuízNavarro, 2004) e outros foram ainda mais subjetivos na escolha dos artigos a analisar (Hoskisson et al., 1999; Trahms; Ndofor; Sirmon, 2013), sendo o uso do fator de impacto um critério utilizado e relevante (Acedo; Barroso; Galan, 2006; Shafique, 2013).

A busca foi feita por intermédio das palavraschave a partir de ecolog*, green*, environment*, sustain*, na ferramenta de busca do portal, sendo que o uso do "*" considerou todas as variações dos termos. Foram considerados todos os artigos publicados até 2014. Após a leitura dos títulos e resumos, os artigos coletados foram validados e a amostra final foi obtida como demonstrado na Tabela 1.

Tabela 1- Periódicos e Quantidade de Artigos Selecionados.

\begin{tabular}{|c|c|c|c|c|c|c|c|c|c|c|c|c|}
\hline \multirow{2}{*}{$\#$} & \multirow{2}{*}{ Periódicos } & \multirow{2}{*}{ FI } & \multirow{2}{*}{$\begin{array}{c}1^{\circ} \\
\text { ano no } \\
\text { ISI }\end{array}$} & \multirow{2}{*}{$\begin{array}{l}\text { Tot. de } \\
\text { Art. no } \\
\text { ISI }\end{array}$} & \multirow{2}{*}{$\begin{array}{c}\% \text { do } \\
\text { Periódico }\end{array}$} & \multirow{2}{*}{$\begin{array}{c}\% \mathrm{da} \\
\text { Amostragem }\end{array}$} & \multicolumn{4}{|c|}{$\begin{array}{c}\mathrm{N}^{\circ} \text { de Artigos por Palavras- } \\
\text { Chave* }\end{array}$} & \multirow{2}{*}{ Tot. } & \multirow{2}{*}{$\begin{array}{c}\text { Art. } \\
\text { Escolhidos }\end{array}$} \\
\hline & & & & & & & $\begin{array}{c}\text { Ecolog } \\
*\end{array}$ & $\begin{array}{c}\text { Green } \\
*\end{array}$ & $\begin{array}{c}\text { Environ } \\
*\end{array}$ & $\begin{array}{c}\text { Sustain } \\
\$\end{array}$ & & \\
\hline 1 & $\begin{array}{l}\text { Academy of Management } \\
\text { Review }\end{array}$ & 7,895 & 1983 & 2060 & 1,07 & 7,38 & 220 & 10 & 223 & 28 & 481 & 21 \\
\hline 2 & Journal of Management & 6,704 & 1983 & 1494 & 1,41 & 7,05 & 9 & 3 & 215 & 63 & 290 & 21 \\
\hline 3 & $\begin{array}{l}\text { Journal of Management } \\
\text { Journal }\end{array}$ & 5,906 & 1958 & 3163 & 0,25 & 2,68 & 17 & 15 & 0 & 21 & 53 & 8 \\
\hline 4 & $\begin{array}{l}\text { Amdministrative Science } \\
\text { Quarterly }\end{array}$ & 4,182 & 1956 & 3472 & 0,4 & 4,7 & 71 & 12 & 191 & 7 & 281 & 14 \\
\hline 5 & $\begin{array}{l}\text { Academy of Management } \\
\text { Annals }\end{array}$ & 4,103 & 2007 & 106 & 7,55 & 2,68 & 14 & 0 & 0 & 9 & 23 & 8 \\
\hline 6 & $\begin{array}{l}\text { Asia Pacific Journal of } \\
\text { Management }\end{array}$ & 4,099 & 2008 & 312 & 0 & 0 & 0 & 2 & 0 & 0 & 2 & 0 \\
\hline 7 & $\begin{array}{l}\text { Journal of Management } \\
\text { Studies }\end{array}$ & 3,799 & 1966 & 2508 & 0,73 & 6,38 & 10 & 26 & 0 & 73 & 109 & 19 \\
\hline 8 & Management Journal & 3,787 & 1975 & 1025 & 6,73 & 23,15 & 9 & 27 & 107 & 77 & 220 & 80 \\
\hline 9 & Long Range Planning & 3,667 & 1968 & 4101 & 1,49 & 20,47 & 252 & 21 & 349 & 66 & 688 & 60 \\
\hline 10 & Strategic Management Journal & 3,367 & 1980 & 2158 & 2,64 & 19,13 & 472 & 28 & 506 & 131 & 1137 & 57 \\
\hline 11 & $\begin{array}{l}\text { Strategic Entrepreneurship } \\
\text { Journal }\end{array}$ & 2,724 & 2007 & 176 & 1,7 & 1,01 & 54 & 0 & 33 & 4 & 91 & 3 \\
\hline 12 & $\begin{array}{l}\text { Journal of Economics } \\
\text { Management Strategy }\end{array}$ & 1,781 & 1995 & 608 & 1,48 & 3,02 & 101 & 11 & 53 & 16 & 181 & 10 \\
\hline 13 & Strategic Organization & 1,769 & 2007 & 164 & 2,44 & 1,34 & 34 & 1 & 13 & 3 & 51 & 4 \\
\hline \multicolumn{11}{|c|}{ Total de Artigos (a partir das palavras-chaves) } & \multicolumn{2}{|l|}{3607} \\
\hline \multicolumn{11}{|c|}{ Total Artigos Usados na Amostra após Leitura e Classificação } & \multicolumn{2}{|r|}{305} \\
\hline \multicolumn{11}{|c|}{ Porcentagem dos Artigos Aproveitados } & \multicolumn{2}{|r|}{$8,46 \%$} \\
\hline
\end{tabular}




\section{Amostra}

A partir dos procedimentos de coletas de dados chegou-se à quantidade de 3607 artigos para análise, divididos em 13 periódicos (Tabela 1). Realizou-se a leitura e seleção prévia chegando à amostra final de 305 artigos relacionados ao tema Estratégia e
Sustentabilidade $(8,46 \%$ dos artigos inicialmente coletados). O período amostral foi de 43 anos (1971 a 2014). A Figura 1 apresenta a evolução de artigos selecionados sobre o tema Estratégia e Sustentabilidade neste período.

Figura 1 - Evolução da Amostra ao Longo dos Anos

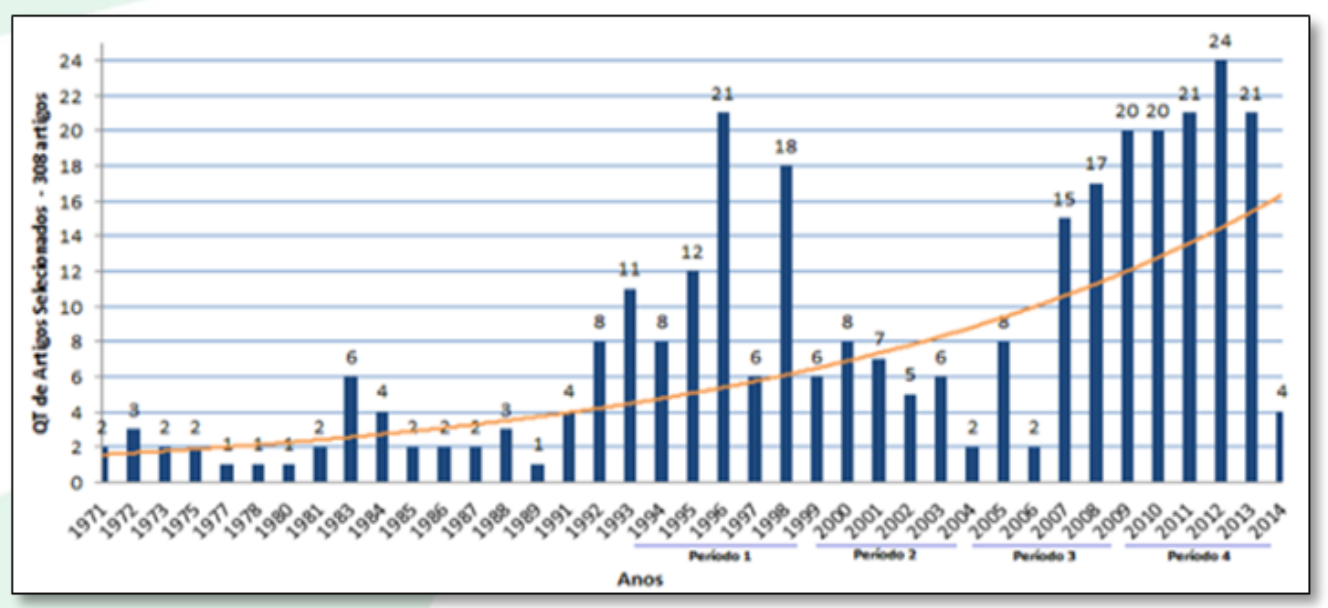

\section{Procedimentos de análise}

Este estudo bibliométrico considerou a análise das citações, cocitações e análise fatorial exploratória para todo o período de vida dos periódicos selecionados (43 anos). Foi realizada ainda a análise fatorial exploratória para os períodos mais recentes (1994-1999; 2000-2004; 2005- 2009; 2010- 2014). A análise de citações compreendeu a coleta de todas as referências dos artigos da amostra, sendo estas classificadas, ordenadas e elencadas (Tabela 2).

$\mathrm{Na}$ sequência elaborou-se a análise fatorial exploratória com rotação Varimax (Acedo, Barroso, \& Galan, 2006; Lin \& Cheng, 2010; Ferreira, Storopoli \& Serra, 2014) utilizando as citações mais frequentes do período total, na intenção de se identificar os principais tópicos em Estratégia e Sustentabilidade abordados por elas. Depois se procedeu á análise para os períodos de tempo mais recentes. De acordo com os resultados da análise fatorial, foram considerados os artigos que se aproximaram conceitualmente num determinado fator, representando um subtema de Estratégia e Sustentabilidade. A análise das cocitações foi avaliada para o período total através do procedimento MDS (Multi Dimensional Scaling), na intensão de ajudar na avaliação da estrutura intelectual sobre o tema e a relação entre os artigos, ou seja, autores e abordagens teóricas (McCain, 1986; Ramos-Rodríguez; RuízNavarro, 2004; Lin; Cheng, 2010a). No mapa resultante a proximidade entre as figuras representou $\mathrm{o}$ relacionamento entre as citações individuais. O mapa MDS foi preparado pelo software SPSS versão 18 .

\section{RESULTADOS E DISCUSSÕES}

\section{Análise das citações}

A análise das citações compreendeu a coleta de todas as referências dos 305 artigos da amostra, sua classificação e ordenamento decrescente das mais para as menos frequentes. Estão apresentadas na Tabela 2, as 30 referências que tiveram frequência de citação acima de 17 citações (critério arbitrado), representando os trabalhos que mais influenciaram intelectualmente a temática no período de 1971 a 2014. 
Tabela 2 - Frequência de Citações

\section{Frequência de Citações}

$1^{\circ}$ - Barney (1991) - 48 citações; $2^{\circ}$ - Porter (1990) - 45 citações; $3^{\circ}$ - Hart (1995) - 44 citações; $4^{\circ}$ - Pfeffer, \& Salancik (1978) - 40 citações; $5^{\circ}$ - Russo, \& Fouts (1997) - 34 citações; $6^{\circ}$ - Porter, \& Linde (1995) - 31 citações; $7^{\circ}$-Thompson (1967) - 30 citações; $8^{\circ}$ - Wernerfelt (1984) - 30 citações; $9^{\circ}$ - Cyert, \& March (1963) - 28 citações; 10 - Dierickx, \& Cool (1989) - 28 citações; $11^{\circ}$ - Barney (1989b) - 26 citações; $12^{\circ}$ Klassen, \& McLaughlin (1996) - 26 citações; $13^{\circ}$ DiMaggio, \& Powell (1983) - 25 citações; 14º - Christmann (2000) - 24 citações; 15 - Schmiheiny (1992) - 23 citações; $16^{\circ}$ - Reed, \& DeFillippi (1990) - 23 citações; $17^{\circ}$ - Meyer, \& Rowan (1977) - 23 citações; $18^{\circ}$ Lippman, \& Rumelt (1982) - 22 citações; $19^{\circ}$ - Winter, \& Nelson (1982) - 22 citações; $2^{\circ}$ - Charma, \& Vredenburg (1998) - 19 citações; $21^{\circ}$ - Waddock, \& Graves (1997) - 19 citações; 22 - March, \& Simon (1958) - 19 citações; 23 - Schoemaker, \& Amit

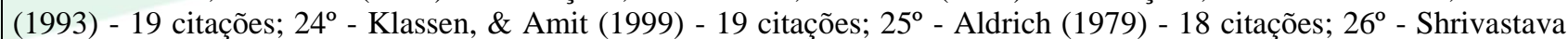
(1995) - 18 citações; $27^{\circ}$ - Miles, Snow, Meyer, \& Coleman (1978) - 18 citações; $28^{\circ}$ - Sharma (2000) - 17 citações; $29^{\circ}$ - Hannan, \& Freeman (1977) - 17 citações; 30 - Gladwin, Kennelly, \& Krause (1995) - 17 citações

\section{Análise fatorial exploratória}

Utilizou-se a análise fatorial exploratória para a verificação da orientação de subtemas relacionados á Estratégia e Sustentabilidade (Lin \& Cheng, 2010) na amostra formada pelos artigos mais citados no período amostral. Iniciou-se pelos artigos mais citados no período total da amostra. Após foi realizada a análise fatorial exploratória para os períodos mais recentes de tempo na intenção de compreender as evoluções e conexões sobre os temas de Estratégia e Sustentabilidade.

$\mathrm{Na}$ Tabela 3 encontram-se os resultados da análise fatorial exploratória, com a apresentação por fator e carga fatorial, para todo o período da amostra, correspondendo a $62,44 \%$ da variância, considerada adequada e com quantidade de fatores (três) que facilitam a organização em subtemas orientativos.

Tabela 3 - Análise Fatorial para o período total da amostra

\begin{tabular}{|c|c|}
\hline \multicolumn{2}{|r|}{ Período 1971 a 2014} \\
\hline Fatores / Subtemas & Referências por Fator \\
\hline $\begin{array}{l}\text { Fator 1 - } \\
\text { Sustentabilidade e } \\
\text { Competitividade }\end{array}$ & $\begin{array}{l}\text { Freeman, \& McVea (1984) - 0,889; Hart, \& Ahuja (1996) - 0,884; Christmann (2000) - } \\
\text { 0,879; Klassen, \& Whybark (1999) - 0,872; Klassen, \& MClauglin (1996) - 0,863; Russo, \& } \\
\text { Fouts (1997) - 0,844; Bansal, \& Clelland (2004) - 0,840; Hart (1997) - 0,825; Bansal,\& Roth } \\
\text { (2000) - 0,813; Bansal (2005) - 0,813; Mitchell, Agle, \& Wood (1997) - 0,790; Gladwin, } \\
\text { Kennelly, \& Krause (1995) - 0,789; Hart (1995) - 0,778; King, \& Lenox (2002) - 0,773; } \\
\text { Porter, \& Linde (1995) - 0,768; Schmidheiny (1992) - 0,727; King, \& Lenox (2000) - 0,691; } \\
\text { Henriques, \& Sadorsky (1999) - 0,686; Walley (1994) - 0,683; Suchman (1995) - 0,675; } \\
\text { Shrivastava (1995) - 0,647; Starik, \& Rands (1995) - 0,638; Sharma, \& Henriques (2005) - } \\
\text { 0,633; Sharma (2000) - 0,631; Oliver (1991) - 0,629; Friedman (1970) - 0,600; Meyer (1977) } \\
\text { - 0,550; Dimaggio, \& Powell (1983) - 0,530; Fornell, \& Larcker (1981) - 0,513; Sharma, \& } \\
\text { Vredenburg (1998) - 0,536. }\end{array}$ \\
\hline $\begin{array}{c}\text { Fator } 2 \text { - Recursos, } \\
\text { Capabilities e } \\
\text { Vantagem } \\
\text { Competitiva }\end{array}$ & $\begin{array}{l}\text { Amit, \& Shoemaker (1993) - 0,908; Itami, \& Roehl (1987) - 0,898; Penrose (1959) - 0,894; } \\
\text { Barney (1986) - 0,889; Reed, \& DeFillippi (1990) - 0,876; Dierickx, \& Cool (1989) - 0,864; } \\
\text { Barney (1986b) - 0,863; Rumelt, Schendel, \& Teece (1991) - 0,860; Peteraf (1993) - 0,856; } \\
\text { Lippman (1982) - 0,847; Williamson (1985) - 0,846; Wernerfelt (1984) - 0,834; Nelson, \& } \\
\text { Winter (1982) - 0,796; Kogut, \& Zander (1992) - 0,790; Porter (1990) - 0,779; Leonard- } \\
\text { Barton (1992) - 0,747; Barney (1991) - 0,719; Hamel, \& Prahalad (1994) - 0,683; Porter } \\
\text { (1980) - 0,662; March, \& Simon (1991) - 0,593; Teece, Pisano, \& Shuen (1997) - 0,144. }\end{array}$ \\
\hline $\begin{array}{l}\text { Fator } 3 \text { - Influência } \\
\text { do Ambiente na } \\
\text { Vantagem } \\
\text { Competitiva } \\
\text { considerando a } \\
\text { Sustentabilidade }\end{array}$ & $\begin{array}{l}\text { Child (1972) - 0,839; Aldrich (1979) - 0,815; Duncan (1972) - 0,768; Hofer, \& Schendel } \\
\text { (1978) - 0,763; Thompson (1967) - 0,761; Hannan, \& Freeman (1977) - 0,754; Dess, \& Beard } \\
\text { (1984) - 0,733; Cyert, \& March (1963) - 0,729; Williamson (1975) - 0,693; Miles, Snow, } \\
\text { Meyer, \& Coleman (1978) - 0,686; Andrews (1971) - 0,657; Hannan, \& Freeman (1984) - } \\
\text { 0,650; Pfeffer, \& Salancik (1978) - 0,625; March, \& Simon (1958) - 0,623; Lawrence, } \\
\text { Lorsch, \& Garrison (1967) - 0,619; Hannan, \& Freeman (1989) - 0,564; Hambrick, \& Mason } \\
\text { (1984) - 0,527; Daft, \& Weick (1984) - 0,510. }\end{array}$ \\
\hline
\end{tabular}

Nota. Os valores correspondem às cargas fatoriais. 
O Fator 1 "Sustentabilidade e Competitividade" se refere à gestão mais consciente e colaborativa, prescrição que muitas vezes resultou da expressão na literatura "vale a pena ser verde", onde os gestores devem fazer investimentos para reduzir o impacto ambiental da sua empresa (Hart, \& Ahuja, 1996). Temas como responsabilidade social corporativa foram introduzidos, afirmando que tal orientação se referiu ao comprometimento da empresa em participar das soluções para os problemas sociais. A integração com os stakeholders e estratégias verdes foram ferramentas fundamentais que permitiram à empresa mostrar uma visão mais ampla de sua gestão de riscos e oportunidades dentro de uma atitude consciente, discutindo temas como: consumo de água, alterações climáticas e pobreza extrema, entre outros.

No Fator 2 "Recursos, Capabilities e Vantagem Competitiva", apareceram questões como Estratégia e Performance Organizacional, Gerenciamento Estratégico e Vantagem Competitiva e a geração de ambas, sendo esse um dos principais construtos do campo da estratégia (Amit, \& Shoemaker, 1993).

No Fator 3 "Influência do Ambiente na Vantagem Competitiva Considerando a Sustentabilidade", os artigos estimularam uma análise crítica das desigualdades sociais em um cenário de constantes modificações. Essa conscientização incitou a responsabilidade social atribuindo às organizações uma postura ética e comprometida com o resgate da cidadania e sobre formulações de estratégia, gestão, controle externo das organizações e a ligação entre os recursos da empresa e a vantagem competitiva sustentável.

\section{Análise fatorial no período de 1995 a 1999.}

$\mathrm{Na}$ análise deste período apareceram 3 fatores. Os temas discutidos nos artigos que integraram o Fator 1 "RBV, Estratégia da Firma, Desempenho da Firma, Gerenciamento Estratégico, Gestão Ambiental e Vantagem Competitiva" tenderam a identificar o desempenho de sustentabilidade que a empresa quer atingir, a ligação com a estratégia de negócios e a intenção inicial de se explicar como a estratégia apresentada pode aumentar o valor da empresa, como por exemplo, através da inovação. No Fator 2 "Teoria da Firma; Organization Fields; Economia, Estratégia Competitiva, Vantagem Competitiva, e Organization" observaram-se discussões sobre emergência e difusão da consciência sustentável na qual se pode recorrer para tornar objetivas as diferentes representações e ideias. $\mathrm{O}$ argumento central desenvolvido pelos economistas em favor da sustentabilidade girou em torno da noção de eficiência no uso dos recursos de forma inespecífica. No Fator 3 "Gestão Estratégica, RBV, Controle Externo e Organizações", os temas se concentraram nos campos da organização, controle e redução de custos e articulações sobre modelos de negócio para os ambientes externos.

Tabela 4 - Análise Fatorial Período 1995 a 1999.

\begin{tabular}{|c|c|}
\hline \multicolumn{2}{|r|}{ Período 1994 a 1999} \\
\hline Fatores / Subtemas & Referências por Fator \\
\hline $\begin{array}{l}\text { Fator } 1 \text { - RBV; Estratégia da } \\
\text { Firma; Desempenho da Firma; } \\
\text { Gerenciamento Estratégico; } \\
\text { Gestão Ambiental; Vantagem } \\
\text { Competitiva. }\end{array}$ & $\begin{array}{l}\text { Itami, \& Roehl (1987) - 0,866; Rumelt (1987) - 0,853; Hart (1995) - 0,802; } \\
\text { Schoemaker, \& Amit (1993) - 0,767; Walley (1994) - 0,743; Schmidheiny (1992) } \\
\text { - 0,737; Reed, \& DeFillippi (1990) - 0,724; Wernerfelt (1984) - 0,709; Lieberman, } \\
\text { \& Montgomery (1988) - 0,702; Dierickx, \& Cool (1989) - 0,674; Barney (1991) - } \\
\text { 0,642; Rumelt, Schendel, \& Teece (1991) - 0,473. }\end{array}$ \\
\hline $\begin{array}{l}\text { Fator } 2 \text { - Teoria da firma; } \\
\text { Organization Fields; Economia; } \\
\text { Estratégia Competitiva; } \\
\text { Vantagem Competitiva; } \\
\text { Organization. }\end{array}$ & $\begin{array}{l}\text { Dimaggio, \& Powell (1983) - 0,868; Granovetter (1985) - 0,775; Cyert (1963) - } \\
\text { 0,72; Thompson (1967) - 0,673; Porter (1985) - 0,637; Porter (1980) - 0,395. }\end{array}$ \\
\hline $\begin{array}{l}\text { Fator } 3 \text { - Gestão Estratégica; } \\
\text { RBV; Controle Externo; } \\
\text { Organizações. }\end{array}$ & $\begin{array}{l}\text { Andrews (1971) - 0,649; Barney (1986) - 0,542; Pfeffer, \& Salancik (1978) - } \\
0,437 \text {. }\end{array}$ \\
\hline
\end{tabular}

Nota. Os valores correspondem às cargas fatoriais.

Análise fatorial no período de 2000 a 2004.

Na análise deste período também apareceram 3 fatores. No Fator 1 "Estratégias Verdes,
Sustentabilidade Corporativa e Gerenciamento Estratégico", a gestão estratégica considerou pontos essenciais no debate do desenvolvimento sustentável, que se referiram à decisão sobre as responsabilidades, 
estratégias verdes (Hart, 1995) e métodos para atingir o desenvolvimento da sustentabilidade, redefinição de riqueza e progressos face a uma visão de vida e de sociedade mais integrada e sistêmica. No Fator 2 "RBV, Teoria da Firma e Estratégias Verdes", observou-se uma possível inclinação para o tema " Teoria da Firma Sustentável", pois os autores que compuseram este fator, de forma geral, discorrem sobre temáticas que envolvem a Teoria da Firma. Ainda os temas centrados na geração de ganhos econômicos (Winter e Nelson 1982), frente a uma temática da multiplicidade conceitual do desenvolvimento sustentável, busca pelo equilíbrio, interdependência, interdisciplinaridade e entendimento da complexidade frente a temas administrativos e estratégicos (Teece, Pisano \& Shuen, 1997) sobre as competências das organizações como da capacidade de aprendizagem, de empreender inovações gerenciais, novos modelos de gestão e da capacidade gerenciamento também foram abordados neste fator. No Fator 3 "Vantagem Competitiva, Estratégia e Teoria de Escolhas Estratégicas", tratou de temas como escolhas estratégicas e sua participação no processo de aprendizagem organizacional adaptado ao ambiente externo e a situação de política interna.

Tabela 5 - Análise Fatorial - Período 2000 a 2004

\begin{tabular}{|c|l|}
\hline \multicolumn{2}{|c|}{ Período 2000 a 2004} \\
\hline Fatores / Subtemas & \multicolumn{1}{|c|}{ Referências por Fator } \\
\hline $\begin{array}{c}\text { Fator 1 - Estratégias Verdes; } \\
\text { Sustentabilidade Corporativa; } \\
\text { Gerenciamento Estratégico. }\end{array}$ & $\begin{array}{l}\text { Gladwin, Kennelly, \& Krause (1995) - 0,855; Russo, \& Fouts (1997) - 0,839; Hart } \\
(1997)-0,829 ; \text { Porter, \& Linde (1995) - 0,774; Shrivastava (1995) - 0,774; Hart } \\
(1995)-0,769 ; \text { Starik, \& Rands (1995) - 0,768. }\end{array}$ \\
\hline $\begin{array}{c}\text { Fator 2 - RBV; Teoria da } \\
\text { Firma; Estratégias verdes. }\end{array}$ & $\begin{array}{l}\text { Barney (1991) - 0,878; Barney (1986) - 0,835; Cyert, \& March (1963) - 0,716; Teece, } \\
\text { Pisano, \& Shuen (1997) - 0,679; Winter, \& Nelson (1982) - 0,634; Lippman (1982) - } \\
0,518 ; \text { Grant (1996) - 0,515; Wernerfelt (1984) - 0,302. }\end{array}$ \\
\hline $\begin{array}{c}\text { Fator 3 - Vantagem } \\
\text { Competitiva; Estratégia; } \\
\text { Teoria Escolhas Estratégicas. }\end{array}$ & $\begin{array}{l}\text { Fredrickson (1984) - 0,868; Duncan (1972) - 0,692; Child (1972) - 0,689; March, \& } \\
\text { Simon (1958) - 0,527; Porter (1980) - 0,482. }\end{array}$ \\
\hline
\end{tabular}

Nota. Os valores correspondem às cargas fatoriais.

\section{Análise fatorial no período de 2005 a 2009}

Na análise deste período também apareceram 3 fatores. Temas anteriores retornaram com uma visão mais abrangente no Fator 1 "Responsabilidade Social Corporativa, Competitividade Verde, Controle Externo das Organizações, Gestão Ambiental, Sustentabilidade Corporativa e Desenvolvimento Sustentável/RBV", pois os recursos externos de organizações (Pfeffer \& Salancik, 1978) podem afetar o comportamento da organização (Hart \& Ahuja, 1996). Os autores concentrados neste fator, de modo generalista, sugeriram a utilização do ambiente externo para informar a visão de longo prazo da empresa e para integrar a sustentabilidade aos modelos e estratégias de negócio. No Fator 2 "RBV, Teoria da Firma e Estratégias Verdes", temas novos emergiram de forma generalista como: aperfeiçoamento das operações enfocando questões ambientais, prevenção da poluição, implementação de novas tecnologias ambientais, colaboração na cadeia de suprimentos para redução dos impactos ambientais (Buysse \& Verbeke, 2003) e orientação em busca da cadeia de suprimentos sustentável. No Fator 3 "RBV e Stakeholders", os autores argumentaram que a estratégia socioambiental proativa (Sharma \& Henriques, 2005) promoveu a prevenção ambiental a partir de uma combinação de recursos, por meio dos quais as empresas desenvolvem capacidades socioambientais. O desenvolvimento sustentável demandou das empresas a construção de capacitação dos funcionários (Sharma \& Vredenburg, 1998), participação em projetos comunitários e ambientais, além das tarefas proteção e conservação ambiental inerente as suas atividades. 
A Pesquisa em Estratégia e Sustentabilidade: Proposta de Agenda de Pesquisa a Partir de um Estudo Bibliométrico

Tabela 6 - Análise Fatorial - Período 2005 a 2009

\section{Período 2005 a 2009}

\begin{tabular}{|c|l|}
\hline Fatores / Subtemas & \multicolumn{1}{|c|}{ Referências por Fator } \\
\hline Fator 1 - Respons. Social & Pfeffer, \& Salancik (1978) - 0,872; Waddock, \& Graves (1997) - 0,843; Barney \\
Corporativa; Competitividade & $(1991)$ - 0,812; Gladwin, Kennelly, \& Krause (1995) - 0,789; Porter, \& Linde (1995) \\
Verde; Controle Externo das & $-0,782 ;$ Klassen, \& MClauglin (1996) - 0,774; Klassen, \& Whybark (1999) - 0,773; \\
$\begin{array}{c}\text { Organiz; Gestão ambiental; } \\
\text { Sustentab. Corporativa; }\end{array}$ & Russo, \& Fouts (1997) - 0,573; Hart, \& Ahuja (1996) - 0,533; Bansal, \& Roth (2000) \\
Desenv. Sustentável/RBV. & $-0,49$. \\
\hline Fator 2 - RBV; Teoria da & Henriques, \& Sadorsky (1999) - 0,9; Bansal (2005) - 0,762; Buyss, \& Verbeke \\
Firma; Estratégias Verdes. & (2003) - 0,74; Aragon-Correa (1998) - 0,615; Hart (1995) - 0,571; Christmann (2000) \\
\hline Fator 3 - RBV; Stakeholder. & $-0,335 ;$ \\
\hline
\end{tabular}

Nota. Os valores correspondem às cargas fatoriais

]

\section{Análise fatorial no período de 2010 a 2014}

Do total de artigos analisados na amostra, 90 deles surgiram de 2010-2014. O período parece ser importante para análise, pois representou um incremento de $29,22 \%$ na produção acadêmica de Estratégia e Sustentabilidade. Este resultado refletiu o crescimento do interesse pelo tema a partir do ano de 2010 .

Neste período foram considerados 4 fatores. No Fator 1 "RBV, Estratégia Corporativa Ambiental, Inovação Verde, Gestão Ambiental e Vantagem Competitiva", as corporações deveriam administrar seus resultados (Molina-Azorin, Claver-Cortês, LópezGamero \&Tari, 2009) com foco nos dados econômicos, acrescentando análises sociais e ambientais nas suas atividades diárias. A gestão ambiental dizia respeito à completa incorporação de objetivos e estratégias ambientais aos objetivos e estratégias mais amplos existentes na organização (Haden, Oyler, \& Humphreys, 2009) em parceria com boas práticas governamentais, incorporando uma visão de negócios voltada às práticas em longo prazo.

No Fator 2, "Estratégia Ambiental e Gestão de Desempenho Organizacional e Social", a gestão dos negócios deveria expressar o compromisso efetivo de todos os graus hierárquicos das organizações permanentemente e o compromisso de seus colaboradores deveria exprimir a qualidade da inserção desta nova realidade na cultura organizacional. A efetiva prevenção da poluição requereria intensivo envolvimento das pessoas (Hart \& Milstein, 2003), bem como o desenvolvimento de capacidades no âmbito da melhoria contínua e gestão da qualidade ambiental. A empresa exerceria papel importante na comunidade e suas ações poderiam mudar a realidade desta.

Observou-se no Fator 3, "Ecodesign, Campos Organizacionais, Stakeholders, Controle Externo das Organizações e Design Tecnologia Limpa", que temas como desenvolvimento empresarial sustentável e seus determinantes organizacionais, bem como fatores baseados em recursos institucionais, poderiam influenciar o desenvolvimento empresarial sustentável. A escolha organizacional seria limitada por uma variedade de pressões externas (Pfeffer, \& Salancik, 1978), os ambientes seriam coletivos e interconectados (Dimaggio, \& Powell, 1983; Pfeffer, \& Salancik, 1978), e as organizações deveriam ser sensíveis às demandas e expectativas externas para sobreviverem (Pfeffer, \& Salancik, 1978).

O Fator 4, "Capabilities, Modelo Econômico de Crescimento e Responsabilidade Social Corporativa", apresentou temas como capacidades dinâmicas, rotinas organizacionais e estratégicos (Eisenhardt, \& Martin, 2000), pelos quais as empresas deveriam alcançar novas configurações de recursos integrando a RBV. A instabilidade do mercado forçaria as empresas a buscarem novas estratégias de negócios e a evolução dessas capacidades dinâmicas dentro da empresa seriam únicas (McWilliams e Siegel 2001). Também a vantagem competitiva não residiria nas capacidades dinâmicas em si, mas sim nas configurações de recursos gerenciais para construção dessas capacidades dinâmicas. 
A Pesquisa em Estratégia e Sustentabilidade: Proposta de Agenda de Pesquisa a Partir de um Estudo Bibliométrico

Tabela 7 - Análise Fatorial - Período de 2010 a 2014

\begin{tabular}{|c|c|}
\hline \multicolumn{2}{|r|}{ Período 2010 a 2014} \\
\hline Fatores / Subtemas & Referências por Fator \\
\hline $\begin{array}{l}\text { Fator } 1 \text { - RBV; Estratégia } \\
\text { Corp. Ambiental; Inovação } \\
\text { Verde; Gestão ambiental; } \\
\text { Vantagem Competitiva. }\end{array}$ & $\begin{array}{l}\text { Chen (2008b) - 0,899; Dwyer (2009) - 0,899; Haden, Oyler, \& Humphreys (2009) - } \\
\text { 0,899; Lee (2009) - 0,899; Molina-Azorín, Claver-Cortés, López-Gamero, \& Tarí } \\
\text { (2009) - 0,886; Chen, Lai \& Wen (2006) - 0,881; Chen (2008) - 0,88; Hair (1998) - } \\
\text { 0,876; Fornell, \& Larcker (1981) - 0,857; Porter (1985) - 0,838; Berry, \& Rondinelli } \\
\text { (1998) - 0,769; Donaldson, \& Preston (1995) - 0,737; Barney (1991) - 0,586; } \\
\text { Mitchell, Agle, \& Wood (1997b) - 0,503; Freeman (1984) - 0,436. }\end{array}$ \\
\hline $\begin{array}{c}\text { Fator } 2 \text { - Estratégia } \\
\text { Ambiental e Gestão } \\
\text { Desempenho Organizacional } \\
\text { Social. }\end{array}$ & $\begin{array}{l}\text { Klassen, \& MClauglin (1996) - 0,827; Bansal, \& Clelland (2004) - 0,792; Klassen, \& } \\
\text { Whybark (1999) - 0,766; King, \& Lenox (2002) - 0,749; Toffel, \& Marshall (2004) - } \\
\text { 0,735; Aiken, West, \& Reno (1991) - 0,715; Christmann (2000) - 0,698; Melnyk, } \\
\text { Sroufe, \& Calantone (2003) - 0,688; Sharma (2000) - 0,687; Montabon, Sroufe, \& } \\
\text { Narasimhan (2007) - 0,666; King, \& Lenox (2000) - 0,613; Sharma, \& Henriques } \\
\text { (2005) - 0,607; Russo, \& Fouts (1997) - 0,595; Waddock, \& Graves (1997) - 0,578; } \\
\text { Mcwilliams (2000) - 0,564; Henriques, \& Sadorsky (1999) - 0,539; Hart (1995) - } \\
\text { 0,479. }\end{array}$ \\
\hline $\begin{array}{c}\text { Fator } 3 \text { - Ecodesign; Campos } \\
\text { Organiz.; Stakeholder; } \\
\text { Controle Ext. das Organiz.; } \\
\text { Design Tecnologia Limpa. } \\
\end{array}$ & $\begin{array}{l}\text { Oliver (1991) - 0,874; Suchman (1995) - 0,866; Mitchell, Agle, \& Wood (1997) - } \\
\text { 0,847; Pfeffer, \& Salancik (1978) - 0,837; Dimaggio, \& Powell (1983) - 0,818; Bansal } \\
\text { (2005) - 0,652; Porter (1990) - 0,379. }\end{array}$ \\
\hline $\begin{array}{l}\text { Fator } 4 \text { - Capabilities; } \\
\text { Modelo Econômico de } \\
\text { Crescimento; } \\
\text { Responsabilidade Social } \\
\text { Corporativa. }\end{array}$ & $\begin{array}{l}\text { Wernerfelt (1984) - 0,832; Hillman, \& Keim (2001) - 0,796; McWilliams, \& Siegel } \\
\text { (2001) - 0,691; Jones (1995) - 0,652; McWilliams, Siegel, \& Wright (2006) - 0,649; } \\
\text { Eisenhardt, \& Martin (2000) - 0,389. }\end{array}$ \\
\hline
\end{tabular}

Nota. Os valores correspondem às cargas fatoriais.

\section{Análise de cocitação}

Para melhor compreender a proximidade entre os artigos mais citados e a força de conexão entre os trabalhos, a análise adicional de cocitações foi realizada. Foi utilizado o MDS - Multidimensional Scaling pelo software SPSS versão 18 , no qual a proximidade entre os trabalhos refletiu a sua ligação com o subtema identificado. A representação gráfica do resultado da análise de cocitação pelo MDS, apresentada na Figura 2, permitiu a identificação dos mesmos fatores, ao comparar com resultados da análise fatorial (Tabela 3) e ainda reafirmou os resultados da análise de frequência de citações da Tabela 2.

$\mathrm{Na}$ Figura 2 os círculos maiores representam que autores foram mais citados em relação aos círculos menores. A distância dos círculos indicaram as proximidades quanto ao tema dos artigos. 
Figura 2 - Escalonamento Multidimensional (MDS) - Software SPSS - vs18

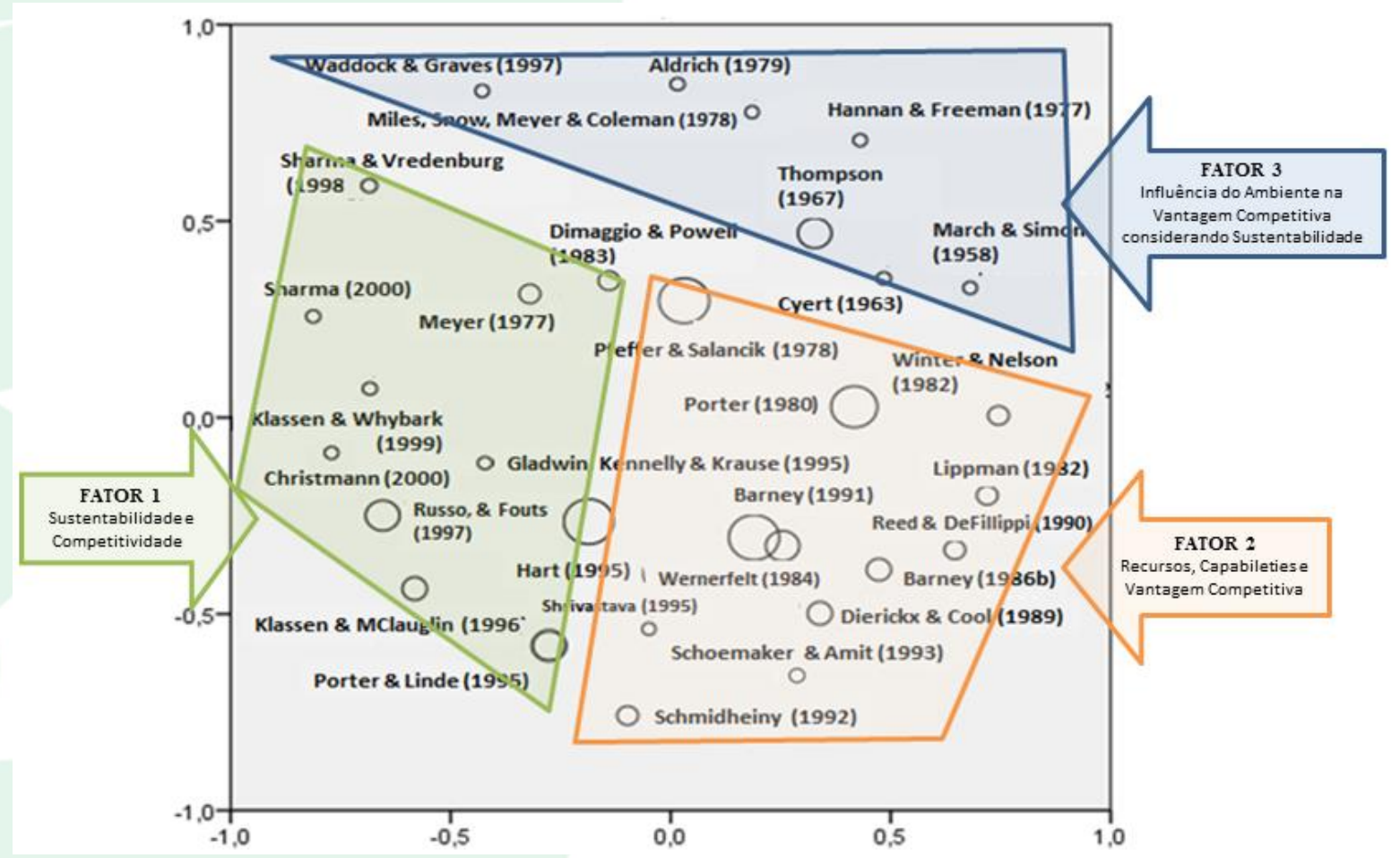

O Fator 1 "Sustentabilidade e Competitividade" na cor verde da Figura 2 foi representado pelos artigos de posição terceira, quinta e sexta na classificação de frequência de citações (Tabela 2). O terceiro e quinto artigos mais citados respectivamente para o período total de Hart (1995) e Russo, \& Fouts (1997), falam sobre a estratégia socioambiental, que é refletida nos valores da empresa e também dos gestores, e que, em seguida, são integrados aos sistemas de gestão e à estratégia do negócio. O sexto artigo mais citado no período total foi o artigo de Porter, \& Van Der Linde (1995). Nele os autores consideraram que as regulamentações ambientais impõem pressões competitivas nas empresas, motivando-as a inovar.

O Fator 2 "Recursos, Capabilities e Vantagem Competitiva" na cor laranja na Figura 2, foi representado pelos artigos na primeira e segunda posição como mais citados no período total (Tabela 2). O primeiro artigo mais citado foi o de Barney (1991) que teve como tema central a sustentabilidade como vantagem competitiva, estabelecendo ainda relações entre os recursos das empresas e a geração de vantagens competitivas sustentáveis. O segundo artigo mais citado foi o de Porter (1980), no qual há conceitos em torno das cinco forças competitivas: rivalidade entre os concorrentes; poder de negociação dos concorrentes; poder de negociação dos clientes; ameaça de produtos substitutos e barreiras à entrada de concorrentes e das três fontes genéricas de vantagem competitiva: diferenciação, custo baixo, foco em mercado específico.

O Fator 3 "Influência do Ambiente na Vantagem Competitiva Considerando a Sustentabilidade", na cor azul da Figura 24, foi representado pelo artigo de quarta posição na frequência de citações (Tabela 2), de Pfeffer, \& Salancik (1978). Este artigo tratou sobre o controle externo das organizações, afirmando que "é o fato da dependência da organização sobre o meio ambiente que faz com que a restrição externa e o controle do comportamento organizacional sejam possíveis e quase inevitáveis".

\section{PROPOSTA DE AGENDA FUTURA}

Com base nos resultados obtidos, propõem-se a realização de uma agenda futura de pesquisas na temática de Estratégia e Sustentabilidade que considere abordagens a discussões sobre a articulação entre estruturas teóricas em administração e economia, centrando-se em temas como: Teoria da Firma; Isomorfismo; Resource and Capabilities; SelfRegulation; Gerenciamento de Recursos e Desempenho da Firma; International Joint Ventures; e Economia Sustentável de Recursos. 
Sugerem-se ainda estudos futuros que aprofundem a discussão de como os sistemas institucionalizados de estratégia e inovação tem contribuído para: Estratégia \& Inovação, Estratégia Organizacional; Vantagem Competitiva; Marketing Verde; Marketing Orientation e Capabilities. Também a especulação sobre temas que envolvam ações das organizações sobre temas como: Sociologia Organizacional; Estrutura Organizacional; Organizational Capabilities; Desempenho Organizacional; Internal structure; Board Composition; Network Resources; e Média Gerência. Estes poderiam ser considerados em estudos futuros como proposta de agenda. Por fim, a abordagem em estudos futuros de temas em crescente discussão como os evidenciados na análise fatorial do Período 4 parecem ser importantes para dar prosseguimento aos estudos de Estratégia e Sustentabilidade, como: Organizações Verdes; Cultura Organizacional; Gestão Ambiental; Certificações e Padrões; RBV; CSR Responsabilidade Social Corporativa; BSC - Balanced Score Card; RBT; Teoria Stakeholder; e Estratégia Social Corporativa Integrada.

A Figura 3 faz o resumo destas temáticas para agenda de trabalhos futuros.

Figura 3 - Mapeamento Temas e Sub-temas para uma Agenda Futura de Pesquisas

\begin{tabular}{|c|c|c|c|c|}
\hline Microfinancas & $\begin{array}{l}\text { Estratégia \& } \\
\text { Inovação }\end{array}$ & Organizations & $\begin{array}{c}\text { Organizações } \\
\text { Verdes }\end{array}$ & $\begin{array}{c}\text { RBV - Resource } \\
\text { Based View }\end{array}$ \\
\hline $\begin{array}{c}\text { Self-regulation } \\
\text { Gerenciamento de } \\
\text { Recursos } \\
\text { Recursos da Firma } \\
\text { Desempenho da Firma; } \\
\text { Financeiro e Recursos; } \\
\text { Program Design } \\
\text { International Joint } \\
\text { Ventures; } \\
\text { Economia Sustentável de } \\
\text { Recursos } \\
\text { Teoria da Firma } \\
\text { Teoria Institucional } \\
\text { Agency Theory } \\
\text { Tecnologia da } \\
\text { Informação } \\
\text { Firm-Information } \\
\text { Systems } \\
\text { T.C.......... }\end{array}$ & $\begin{array}{c}\text { Estratégia } \\
\text { Organizacional } \\
\text { Politica estratégica } \\
\text { Estratégia de } \\
\text { negócios } \\
\text { Gerenciamento } \\
\text { estratégico; } \\
\text { Business } \\
\text { development; } \\
\text { Tomada de decisão } \\
\text { Competitividade } \\
\text { Verde } \\
\text { Vantagem } \\
\text { competitiva } \\
\text { Marketing Verde } \\
\text { Marketing } \\
\text { Orientation } \\
\end{array}$ & $\begin{array}{l}\text { Sociologia } \\
\text { Organizacional } \\
\text { Estrutura } \\
\text { Organizacional } \\
\text { Organizational } \\
\text { Capabilities; } \\
\text { Desempenho } \\
\text { Organizacional } \\
\text { Internal structure } \\
\text { Board Composition } \\
\text { Network Resources } \\
\text { Média Gerencia }\end{array}$ & $\begin{array}{l}\text { Cultura } \\
\text { Organizacional } \\
\text { Consciencia } \\
\text { ambiental; } \\
\text { Organização } \\
\text { Ambiental } \\
\text { Desempenho } \\
\text { Ambiental } \\
\text { Gerenciamento } \\
\text { Ambiental } \\
\text { Gestão Ambiental } \\
\text { Certificações - } \\
\text { Padrões } \\
\text { ISO 14000 } \\
\text { ISO 9001 } \\
\text { Total Quality } \\
\text { Management } \\
\end{array}$ & $\begin{array}{c}\text { CSR - Responsabilidade } \\
\text { Social Corporativa } \\
\text { BSC - Balanced Score } \\
\text { Card } \\
\text { RBT } \\
\text { Desempenho Social- } \\
\text { Ambiental-Econônico } \\
\text { Teoria Stakeholder } \\
\text { Orientação Stakeholder } \\
\text { Gerenciamento dos } \\
\text { Stakeholders } \\
\text { Estratégia Social } \\
\text { Corporativa Integrada } \\
\text { Desenvolvimento } \\
\text { economico Sustentavel } \\
\text { Vantagem competitiva } \\
\text { sustentável } \\
\end{array}$ \\
\hline
\end{tabular}

\section{LIMITAÇÕES DO ESTUDO}

De maneira geral os estudos bibliométricos apresentam uma limitação tradicional relacionada á escolha das palavras chave. Embora a mesma exista, tentou-se minimizar este efeito com a consideração bastante extensa de combinações para busca.

Outra limitação refere-se usualmente á escolha da base de dados para a busca. Ao escolhermos a Web of Science, apesar de ser considerada principal em conhecimento multidisciplinar e em ciências sociais aplicadas e humanas, deixou-se de fazer buscas em outas bases reconhecidas. Numa possível pesquisa futura pode-se ampliar a pesquisa para outras bases.

Finalmente, uma limitação se refere a não consideração dos contextos em que os artigos selecionados foram utilizados pelos autores. Para estudos futuros essa possibilidade de análise contextual poderia ser considerada utilizando-se os próprios artigos como fonte, ou mesmo um estudo bibliométrico de pareamento ou de análise semântica.

\section{CONCLUSÕES}

Os estudos bibliométricos possuem vantagem de possibilitar a seleção e análise quantitativa da pesquisa passada em determinado tema, retirando a subjetividade desta revisão. Então neste trabalho, examinou-se e classificou-se a pesquisa existente em Estratégia e Sustentabilidade utilizando o método bibliométrico com análise de citação, cocitação, análise fatorial exploratória e escalonamento multidimensional (MDS).

Com o objetivo de compreender a estrutura intelectual que conectava estes temas, por meio da análise da produção acadêmica em periódicos de alto fator de impacto na área de Administração e 
Sustentabilidade este trabalho se justificou devido a aparente inexistência de uma revisão que conectasse a relação de estratégia e sustentabilidade, embora muitos pesquisadores reconheçam o tema como um desafio estratégico para as empresas. Neste sentido a questão de pesquisa relacionada a quais seriam os principais temas nas pesquisas sobre Sustentabilidade e Estratégia analisando-se a produção acadêmica cientifica á partir de periódicos de alto fator de impacto foi respondida aplicando-se o método bibliométrico.

Para tanto, foram selecionados na base ISI Web of Science 305 artigos relacionados á Estratégia e Sustentabilidade de 14 periódicos internacionais da área de Administração com alto Fator de Impacto (FI $\geq$ $1,4)$.

Os resultados das análises sobre Estratégia e Sustentabilidade mostraram que houve um incremento de artigos publicados na temática á partir de 2010 e apontaram, através da análise fatorial exploratória, três bases intelectuais que têm influenciado a área: Fator 1: Sustentabilidade e Competitividade; Fator 2: Recursos, Capabilities e Vantagem Competitiva; Fator 3: Influência do Ambiente na Vantagem Competitiva Considerando a Sustentabilidade. As análises fatoriais exploratórias por períodos confirmaram os temas elencados na análise do período total, sendo que no período mais recente, de 2010-2014, apareceram temas novos e modernos como capacidades dinâmicas e rotinas organizacionais e estratégicas.

A identificação e mapeamento dos subtemas nos resultados apresentados apontaram também questões variadas sobre o tema e sua complexidade, sempre relacionados às vantagens competitivas e sua base intelectual em sustentabilidade. Neste sentido, a agenda de trabalhos futuros sugeriu a realização de pesquisas que considerem abordagens e discussões sobre a articulação entre estruturas teóricas em administração e economia, centrando-se em temas como: Teoria da Firma; Isomorfismo; Resource and Capabilities; SelfRegulation; Gerenciamento de Recursos e Desempenho da Firma; International Joint Ventures; e Economia Sustentável de Recursos.

Espera-se que este estudo sirva como contribuição no aprofundamento da discussão sobre a temática Estratégia e Sustentabilidade e que a relevância de disponibilizar uma base que informe os trabalhos realizados, autores influentes e categorias de subtemas seja uma ferramenta facilitadora para muitos pesquisadores.

\section{REFERÊNCIAS}

Acedo, F. J., Barroso, C., \& Galan, J. L. (2006). The resource-based theory: dissemination and main trends. Strategic Management Journal, 27(7), 621636.
Aiken, L. S., West, S. G., \& Reno, R. R. (1991). Multiple regression: Testing and interpreting interactions. Sage.

Amit, R., \& Schoemaker, P. J. (1993). Strategic assets and organizational rent. Strategic management journal, 14(1), 33-46.

Andrews, K. R. (1971). Concept of corporate strategy.

Aragón-Correa, J. \& Sharma, S. (2003). A Contingent Resource-Based View of Proactive Corporate Environmental Strategy. Academy of Management Review, 28(1), 71-88.

Aragón-Correa, J. A. (1998). Strategic proactivity and firm approach to the natural environment. Academy of management Journal, 41(5), 556-567.

Assan, M. A. de C., \& Meira, S. R. (2015). A pesquisa em gestão da sustentabilidade: evolução intelectual e agenda futura a partir de um estudo bibliométrico de citação e cocitação. Workin Paper. UNIJUI Universidade Regional do Noroeste do estado do Rio Grande do Sul, Rio Grande do Sul.

Bansal, P. (2005). Evolving sustainably: A longitudinal study of corporate sustainable development. Strategic management journal, 26(3), 197-218.

Bansal, P., \& Clelland, I. (2004). Talking trash: Legitimacy, impression management, and unsystematic risk in the context of the natural environment. Academy of Management Journal, 47(1), 93-103.

Bansal, P., \& Roth, K. (2000). Why companies go green: A model of ecological responsiveness. Academy of management journal, 43(4), 717-736.

Bansal, P. (2002). The corporate challenges of sustainable development. The Academy of Management Executive, 16(2), 122-131.

Barney, J. B. (1986). Organizational culture: can it be a source of sustained competitive advantage?. Academy of management review, 11(3), 656-665.

Barney, J. (1991). Firm resources and sustained competitive advantage. Journal of management, 17(1), 99-120.

Berry, M. A., \& Rondinelli, D. A. (1998). Proactive corporate environmental management: A new industrial revolution. The Academy of Management Executive, 12(2), 38-50. http://doi.org/10.5465/AME.1998.650515. 
Buysse, K., \& Verbeke, A. (2003). Proactive environmental strategies: A stakeholder management perspective. Strategic management journal, 24(5), 453-470.

Carroll, A. B. (1999). Corporate social responsibility evolution of a definitional construct. Business \& society, 38(3), 268-295.

Chen, J. C., \& Silverthorne, C. (2008). The impact of locus of control on job stress, job performance and job satisfaction in Taiwan. Leadership \& Organization Development Journal, 29(7), 572-582.

Chen, L. H. (2008). Job satisfaction among information system (IS) personnel. Computers in Human Behavior, 24(1), 105-118.

Chen, Y. S., Lai, S. B., \& Wen, C. T. (2006). The influence of green innovation performance on corporate advantage in Taiwan. Journal of business ethics, 67(4), 331-339.

Child, J. (1972). Organizational structure, environment and performance: The role of strategic choice. sociology, 6(1), 1-22.

Christmann, P. (2000). Effects of "Best Practices" of Environmental Management on Cost Advantage: The Role of Complementary Assets. Academy of Management Journal, 43(4), 663-680.

Cyert, R. M., \& March, J. G. (1963). A Behavioral Theory of the Firm: Develops a Theory of the Firm which is Based on Empirical Studies of Decisionmaking Within the Firm. Prentice-Hall.

Cyert R., \& March J. (1963). A behavioral. Theory of the firm. New Jersey: Prentice-Hall, Inc., 1963. pp.332.

Dierickx, I., \& Cool, K. (1989). Asset stock accumulation and sustainability of competitive advantage. Management Science, V.35, $\mathrm{N}^{\mathrm{o}} 12$, $\mathrm{p}$. 1504-1511.

Dimaggio, P. J.; \& Powell, W. W. (1983), The iron cage revisited: institutional isomorphism and collective rationality in organizational fields. American Sociological Review, v.48, n.2, p.147160.

Donaldson, T., \& Preston, L. E. (1995). The stakeholder theory of the corporation: Concepts, evidence, and implications. Academy of management Review, 20(1), 65-91.

Duncan, R. B. (1972). Characteristics of organizational environments and perceived environmental uncertainty. Administrative science quarterly, 313327.

Dunlap, R., \& Mertig, A. (1992). American environmentalism: the US environmental movement, 1970-1990. Recuperado de http://library.wur.nl/WebQuery/clc/580108

Dyllick, T., \& Hockerts, K. (2002). Beyond the business case for corporate sustainability. Business Strategy and the Environment, 11(2), 130-141.

Eisenhardt, K. M., \& Martin, J. A. (2000). Dynamic capabilities: what are they? Strategic management journal, 1105-1121.

Ferreira, M. P., Storopoli, J. E., \& Serra, F. A. R. (2014, January). The Extant Research on Strategic Alliances: A Bibliometric Study of the Past Two Decades. In Academy of Management Proceedings (Vol. 2014, No. 1, p. 10161). Academy of Management.

Fornell, C., \& Larcker, D. F. (1981). Evaluating structural equation models with unobservable variables and measurement error. Journal of marketing research, 39-50.

Fredrickson, J. W. (1984). The comprehensiveness of strategic decision processes: Extension, observations, future directions. Academy of Management journal, 27(3), 445-466.

Freeman, R. E. (1984): Strategic management: a stakeholder approach, Boston: Pitman.

Gladwin, T. N.; Kennely, J.; Krause, T. (1995), Shifting paradigms for sustainable development: Implications for management theory and research, The Academy of Management Review, Mississippi.

Granovetter, M. (1985). Economic action and social structure: The problem of embeddedness. American journal of sociology, 481-510.

Grant, R. M. (1996). Toward a knowledge-based theory of the firm. Strategic management journal, 17(S2), 109-122.

Haden, S. S., Oyler, J. D., \& Humphreys, J. H. (2009). Historical, practical, and theoretical perspectives on green management: An exploratory analysis. Management Decision, 47(7), 1041-1055.

Hahn, T., Figge, F., Liesen, A., \& Barkemeyer, R. (2010). Opportunity cost based analysis of corporate eco-efficiency: A methodology and its application to the $\mathrm{CO}$ 2-efficiency of 
Hart, S. L., \& Milstein, M. B. (1999). Glohal Sustainability and the Creative Destruction of Industries. Sloan Management Review, 41(1), 2333.

Hart, S. and G. Ahuja. (1996). Does it pay to be green? An empirical examination of the relationship between emission reduction and firm performance. Business Strategy and the Environment. 5:30-37.

Hart, S. L., \& Milstein, M. B. (2003). Creating sustainable value. The Academy of Management Executive, 17(2), 56-67.

Shirivastava, P. and Hart, S. (1992). Greening organizations. Academy of Management Best Paper Proceedings, 52: 185-189.

Hart, S. L. (1995). A natural-resource-based view of the firm. Academy of management review, 20(4), 986-1014.

Hart, S. (1997) Strategies for a sustainable world, Harvard Business Review, 75(1): Jan.

Hart, S. (1980) The environmental movement: Fulfullment of the Renaissance prophecy? Natural Resources Journal. 20: 501-522.,

Hart, S. (2005). Capitalism at the crossroads: The unlimited business opportunities in solving the world's most difficult problems. Pearson Education.

Henriques, I., \& Sadorsky, P. (1999). The relationship between environmental commitment and managerial perceptions of stakeholder importance. Academy of management Journal, 42(1), 87-99.

Hillman, A. J., \& Keim, G. D. (2001). Shareholder value, stakeholder management, and social issues: what's the bottom line?. Strategic management journal, 125-139.

Hoskisson, R. E., Hitt, M. A., Wan, W. P., \& Yiu, D. (1999). Theory and research in strategic management: Swings of a pendulum. Journal of management, 25(3), 417-456.

Jones, T. M. (1995). Instrumental stakeholder theory: A synthesis of ethics and economics. Academy of management review, 20(2), 404-437.

Ketchen Jr, D. J., \& Wright, M. (2011). The future of resource-based theory: revitalization or decline? Journal of management, 37(5), 1299-1315.
King, A. A., \& Lenox, M. J. (2000). Industry selfregulation without sanctions: The chemical industry's responsible care program. Academy of management journal, 43(4), 698-716.

King, A., \& Lenox, M. (2002). Exploring the locus of profitable pollution reduction. Management Science, 48(2), 289-299.

Klassen, R. D., \& McLaughlin, C. P. (1996). The impact of environmental management on firm performance. Management science, 42(8), 11991214.

Klassen, R. D., \& Whybark, D. C. (1999). The impact of environmental technologies on manufacturing performance. Academy of Management journal, 42(6), 599-615.

Lee, R. (2009). Social capital and business and management: Setting a research agenda. International Journal of Management Reviews, 11(3), 247-273.

Lieberman, M. B., \& Montgomery, D. B. (1988). First-mover advantages. Strategic management journal, 9(S1), 41-58.

Lin, T. Y., \& Cheng, Y. Y. (2010). Exploring the knowledge network of strategic alliance research: A co-citation analysis. International Journal of Electronic Business Management, 8(2), 152-160. Retrieved from http://140.114.53.122/IJEBM_Web/IJEBM_static/P aper-V8_N2/A07.pdf

Lippman, S. A., \& Rumelt, R. P. (1982). Uncertain imitability: An analysis of interfirm differences in efficiency under competition. The Bell Journal of Economics, 418-438.

March, J. G, \& Simon, H. A. (1958). Organizations.

Mccain, K. W. (1984). Cocited author mapping as a valid representation of intelectual struture. Journal of the Amedican Society for Information Sience 37, p. 433-443.

McGee, J. (1998). Commentary on "corporate strategies and environmental regulations: An organizing framework"by AM Rugman and A. Verbeke. Strategic Management Journal, 19(4), 377-387.

McWilliams, C. (2000). Factories in the field: The story of migratory farm labor in California. Univ of California Press. 
McWilliams, A., \& Siegel, D. (2001). Corporate social responsibility: A theory of the firm perspective. Academy of management review, 26(1), 117-127.

McWilliams, A., Siegel, D. S., \& Wright, P. M. (2006). Corporate social responsibility: Strategic implications. Journal of management studies, 43(1), $1-18$.

Melnyk, S. A., Sroufe, R. P., \& Calantone, R. (2003). Assessing the impact of environmental management systems on corporate and environmental performance. Journal of Operations Management, 21(3), 329-351.

Mitchell, R. K., Agle, B. R., \& Wood, D. J. (1997). Toward a theory of stakeholder identification and salience: Defining the principle of who and what really counts. Academy of management review, 22(4), 853-886.

Molina-Azorín, J. F., Claver-Cortés, E., LópezGamero, M. D., \& Tarí, J. J. (2009). Green management and financial performance: a literature review. Management Decision, 47(7), 1080-1100.

Montabon, F., Sroufe, R., \& Narasimhan, R. (2007). An examination of corporate reporting, environmental management practices and firm performance. Journal of operations management, 25(5), 998-1014.

Nerur, S., Rasheed, A., \& Natarajan, V. (2008). The intellectual structure of the strategic management field: An author co-citation analysis. Strategic Management Journal, 29(3), 319-336.

Oliver, C. (1991). Strategic responses to institutional processes. Academy of management review, 16(1), $145-179$.

Palmer, K., W. $\quad$ E. Oates, and P. R. Portney (1995), Tightening Environmental Standards: The Bennefit-Cost or the No-Cost Paradigm.Journal of Economics Perspectives 2, 119-132.

Pfeffer, J. \& Salancik, G. (1978) External Control of Organizations. A Resource Dependence Perspective.

Porter, M. Press. (1980). Competitive Strategy. New York: The Free.

Porter, M. E. (1985). Competitive advantage: creating and sustaining superior performance. 1985. New York: FreePress.
Porter, M. E. (1990). Competitive Strategy: Techniques for Analyzing Industries and Competitors. New York: Free Press. (Republished with a new introduction, 1998)

Porter, M. \& Van Der Linde, C. (1995). Toward a new conception of the environment-competitiveness relationship. Journal of Economics Perspectives, 9 (4):97-118.

Ramos-Rodríguez, A. R., \& Ruíz-Navarro, J. (2004). Changes in the intellectual structure of strategic management research: A bibliometric study of the Strategic

Reed, R., \& DeFillippi, R. J. (1990). Causal ambiguity, barriers to imitation, and sustainable competitive advantage. Academy of Management Review, 15(1), 88-102.

Rumelt, R. P., Schendel, D., \& Teece, D. J. (1991). Strategic management and economics. Strategic management journal, 12(S2), 5-29.

Russo \& Fouts, P. (1997) A Resource-Based Perspective on Corporate Environmental Performance and Profitability. The Academy of Management Journal, 40(3):534-559.

Schmiheiny, S. (1992). Changing Cours e New York MIT Press.

Schoemaker, P. J. \& Amit, R. (1993). Strategic Assets and Organizational Rent. Strategic Management Journal, Vol.14, 33-46.

Shafique, M. (2013). Thinking inside the box? Intellectual structure of the knowledge base of innovation research (1988-2008). Strategic Management Journal, 34(1), 62-93.

Sharma, S., \& Henriques, I. (2005). Stakeholder influences on sustainability practices in the Canadian forest products industry. Strategic management journal, 26(2), 159-180.

Sharma, S., \& Vredenburg, H. (1998). Proactive corporate environmental strategy and the development of competitively valuable organizational capabilities. Strategic Management Journal, 19(8), 729-753.

Sharma, S. (2000). Managerial interpretations and organizational context as predictors of corporate choice of environmental strategy. Academy of Management Journal, 43(4), 681-697. 
Sharma, A., Moody, P. E., \& Rosa, M. L. G. L. (2003). A máquina perfeita: como vencer na nova economia produzindo com menos recursos. Pearson Education do Brasil.

Shrivastava, P., \& Hart, S. (1994). Greening organizations 2000. The International Journal of Public Administration, 17(3-4), 607-635.

Shrivastava, P. (1995). The role of corporations in achieving ecological sustainability. Academy of Management Review, 20 (4), 936-960.

Starik, M., \& Rands, G. P. (1995). Weaving an integrated web: Multilevel and multisystem perspectives of ecologically sustainable organizations. Academy of Management Review, 20(4), 908-935.

Suchman, M. C. (1995). Managing legitimacy: Strategic and institutional approaches. Academy of management review, 20(3), 571-610.

Teece, D. J., Pisano, G., \& Shuen, A. (1997). Dynamic capabilities and strategic management. Strategic Management Journal, 18(7), 509-533.

Thompson, J. D. (1967). Organizations in Action. New York McGraw-Hill.
Toffel, M. W., \& Marshall, J. D. (2004). Improving environmental performance assessment: a comparative analysis of weighting methods used to evaluate chemical release inventories. Journal of Industrial Ecology, 8(1-2), 143-172.

Trahms, C. A., Ndofor, H. A., \& Sirmon, D. G. (2013). Organizational decline and turnaround a review and agenda for future research. Journal of Management, 39(5), 1277-1307.

Waddock, S. A. \& Graves, S. B. (1997). The corporate social performance-financial performance link. Strategic Management Journal, 18 (4) 303-319.

Wagner, M. (2010). The role of corporate sustainability performance for economic performance: A firmlevel analysis of moderation effects. Ecological Economics, 69(7), 1553-1560.

Walley, N., \& Whitehead, B. (1994). It's not easy being green. Reader in Business and the Environment, 36, 81.

Wernerfelt, B. (1984). A resource-based view of the firm. Strategic Management Journal, 5(2), 171-180.

Winter, S. G. \& Nelson, R. R. (1982). Na evolutionary theory of economic change. University of Illinois at Urbana-Champaign's Academy for Entrepreneurial Leadershio Historical Research. 